\title{
FINANCIAMENTO EXTERNO EM APL: UMA ANÁLISE NO APL DE MÓVEIS DE MÁCEIO/AL
}

\section{EXTERNAL FINANCING IN APL: AN ANALYSIS IN THE FURNITURE APL OF MÁCEIO/AL}

\author{
Carla Cristine Silva Lopes \\ Universidade Federal do Paraná - UFPR \\ carlacslopes@gmail.com \\ Ronalty Rocha \\ Universidade Federal do Paraná - UFPR \\ ronaltyrocha@gmail.com
}

Submissão: 08/12/2021

Aprovação: 29/12/2021

Fast Track no V Encontro Internacional de Gestão, Desenvolvimento e Inovação, da Universidade Federal do Mato Grosso do Sul (UFMS).

\section{RESUMO}

Diante das dificuldades enfrentadas pelas pequenas e médias empresas na obtenção de crédito, essa pesquisa endereçou a seguinte questão: quais barreiras e fatores limitantes impedem o acesso de empresas participantes de APL a financiamentos externos? Nesse cenário, esse estudo tem como objetivo discutir o acesso a financiamentos externos por empresas participantes do Arranjo Produtivo Local (APL) de Móveis de Maceió, Alagoas. Especificamente essa pesquisa buscou identificar as barreiras para prospectar apoio financeiro externo, descrever os fatores limitantes no acesso a crédito, assim como mencionar as ações de apoio desenvolvidas pela gestão do APL. Para alcance dos objetivo proposto foi realizada uma pesquisa qualitativa, por meio de um estudo de caso único integrado, cujas unidades de análise foram duas empresas participantes e a gerência do APL de Móveis de Maceió/AL. Os resultados indicam ampla diversidade de dificuldades enfrentadas pelas empresas, assim como o papel moderador exercido pela entidade gestora do arranjo.

Palavras-chave: Arranjo Produtivo Local (APL), Financiamento externo, Barreiras para apoio financeiro externo.

\begin{abstract}
In view of the difficulties faced by small and medium-sized companies in obtaining credit, this research addressed the following question: what barriers and limiting factors hinder the access of companies participating in APL to external financing? In this context, this study aimed to discuss the access to external financing by companies participating in the Local Productive Arrangement (APL) of Furniture in Maceió, Alagoas. Specifically, it sought to identify the barriers to prospecting external financial support, to describe the limiting factors in the access to credit, as well as to mention the support actions developed by the APL management. To reach
\end{abstract}


the proposed objectives qualitative research was carried out, by means of a single integrated case study, whose units of analysis were two participating companies and the management of the Furniture APL of Maceió/AL. The results indicate a wide diversity of difficulties faced by the companies, as well as the moderating role exercised by the management entity of the arrangement.

Keywords: Local Productive Arrangement (APL), External Financing, Barriers to External Financial Support.

\section{INTRODUÇÃO}

As pequenas e médias empresas (PMEs) que se unem em um mesmo espaço geográfico e angariam vantagem competitiva devido a essa aglomeração espacial são denominadas Arranjos Produtivos Locais (APLs) (MUELLER; JUNWIRTH, 2020).

Sobre esses aglomerações, Rocha e Olave (2019) informam que os arranjos produtivos locais são objeto de notável relevância na elaboração de políticas públicas e na ação empreendedora dos empresários, que já reconhecem os robustos benefícios proporcionados às empresas participantes de tais aglomerações.

Complementando essa percepção, Balestrin e Verschoore (2008) sintetizam que a participação em APLs tem o potencial de atribuir vantagem competitiva às empresas, que passam a ter acesso a mão de obra especializada, proximidade física com clientes e fornecedores, assim como produção e compartilhamento de tecnologias e conhecimentos (TIZZIOTI et al., 2019).

Nesse ínterim, acrescenta-se que, embora os APLs possam ser formados por empresas de diferentes portes, predomina a presença de pequenos negócios (SIMONETTI; KAMIMURA; OLIVEIRA, 2015), que conforme tem sido discutido, são relevante ao desenvolvimento econômico das nações (HERR; NETTEKOVEN, 2017), especialmente no Brasil, em que representam $30 \%$ do produto interno bruto do país e são responsáveis por mais da metade dos empregos formais gerados (SEBRAE, 2020).

Por outro lado, mesmo diante da relevância dos pequenos negócios para o desenvolvimento econômico, essas empresas enfrentam dificuldades no acesso a financiamentos e linhas de crédito (SEBRAE, 2017), o que tem prejudicado o desenvolvimento e crescimento desses empreendimentos (CERBUSCA, 2015).

Consequentemente, como são escassos os recursos financeiros destinados a essas empresas, a participação em arranjos produtivos locais emerge como uma alternativa para acessar soluções financeiras (VERSHOORE; BALESTRIN, 2008), compartilhamento de recursos financeiros (MARTINS; FARIAS; FARINA, 2016) e superação de dificuldades no acesso ao crédito (BRITTO; VARGAS; CASSIOLATO, 2001).

Um desses prováveis APLs que as empresas tem buscado para acessar recursos financeiros é o Arranjo Produtivo Local de Móveis de Maceió e Entorno (Alagoas). Reconhecido em 2013, esse APL beneficia ao menos 70 empresas, oferecendo apoio em ações de capacitação, fornecimento de mão de obra qualificada, estímulo ao empreendedorismo, associativismo e consultoria, além de gerar emprego e renda para a população local (AGÊNCIA ALAGOAS, 2018).

Diante do exposto, esse estudo endereçou a seguinte questão: Quais barreiras e fatores limitantes impedem o acesso de empresas participantes de APL a financiamentos externos? Para responder a essa pergunta, o objetivo da pesquisa é discutir o acesso a financiamentos externos por empresas participantes do Arranjo Produtivo Local- APL de Móveis de Maceió e Entorno (Alagoas). Especificamente essa pesquisa buscou identificar as barreiras para prospectar apoio financeiro externo, descrever os fatores limitantes no acesso a crédito externo, assim como 
mencionar as ações de apoio desenvolvidas pela gestão do APL.

Merece destacar que no contexto das aglomerações espaciais, a exemplo dos APLs, algumas das últimas pesquisas tem debatido as fontes de financiamento para inovação (REVZON; POCHEKUTOV; AKSYONOVA, 2021); comparado estruturas de financiamento entre aglomerações industriais e de serviços (BURGER, 2018); assim como discutido a centralização ou descentralização de financiamentos públicos para aglomerações produtivas (URBANČÍKOVÁ; BURGER, 2016).

Em contrapartida, conforme levantamento preliminar na base de dados SPELL, não foram localizados estudos que tratassem diretamente de financiamento em arranjos produtivos locais ${ }^{1}$, corroborando a percepção de Carvalho (2005) de que essa é uma temática com limitada discussão acadêmica no contexto nacional, e consequentemente, destacando a lacuna de pesquisa para esse estudo.

\section{ARRANJO PRODUTIVO LOCAL (APL), PEQUENA EMPRESA E FINANCIAMENTO}

Observa-se que as transformações de mercado têm impulsionado as empresas a atuarem por meio de novas configurações interorganizacionais, influenciando a formação de aglomerações organizacionais (FERREIRA, et al., 2011). Sobre esse assunto, Souza et al., (2020) explicam que essas aglomerações podem ser tipificadas como clusters, distritos industriais e arranjos produtivos locais (APLs).

Esses autores explicam que os clusters se referem a aglomeração territorial de indústrias relacionadas, o distrito industrial é formado pela concentração territorial de empresas e instituições locais, ao passo em que os APLs representam aglomerações produtivas com múltiplos atores econômicos, políticos e sociais que promovem inovação e produção a partir de cooperação e aprendizagem.

Nesse sentido, Lastres e Cassiolato (2003, p. 3) informam que os APL são "aglomerações territoriais de agentes econômicos, políticos e sociais - com foco em um conjunto específico de atividades econômicas - que apresentam vínculos, mesmo que incipientes".

Dessa forma, tem-se que o APL é uma aglomeração de empresas, territorialmente concentradas, que apresentam características de identidade coletiva (sociais, culturais, econômicas, históricas, entre outras) (FERREIRA et al., 2011), que atuam em torno de uma mesma atividade produtiva e que estabelecem vínculos de articulação, interação, cooperação e aprendizagem entre si e com outros atores locais, tais como: governo, associações empresariais, instituições de crédito, ensino e pesquisa (CARDOSO; CARNEIRO; RODRIGUES, 2014).

Consequentemente, Rocha e Olave (2019) sintetizam que os benefícios resultantes da participação em APLs podem ser visualizados em ganhos de escala, geração de inovação, acesso à soluções financeiras, aprendizagem, compartilhamento de recursos financeiros, acesso a novos mercados, equilíbrio mercadológico e sobrevivência empresarial.

Por outro lado, a de se considerar que os APLs são compostos, em sua maioria, por pequenas empresas (SIMONETTI; KAMIMURA; OLIVEIRA, 2015), e que a continuidade empresarial desses negócios depende do acesso a fontes externas de financiamento. Sobre esse assunto, Cerbusca (2015) argumenta que, em sua fase inicial de funcionamento, as pequenas e médias empresas contam principalmente com fontes internas de financiamento, contudo, quando o custo de crescimento dessas empresas ultrapassa a disponibilidade de recursos financeiros dos proprietários, esses empreendimentos passam a depender de fontes externas de financiamento (HUSSAIN; MILLMAN; MATLAY; 2006), que assumem papel de destaque na

\footnotetext{
${ }^{1}$ Levantamento feito em 18 de agosto de 2021.
} 
produtividade e crescimento desses negócios (MOHAMAD et al., 2015).

Considerando a preponderância de financiamentos externos para pequenas e médias empresas, explica-se que as instituições bancárias são as principais fornecedoras de crédito para negócios de pequeno e médio porte, ficando clara a importância da relação entre essas empresas e as instituições concessoras de crédito (DEGRYSE; MASSCHELEIN; MITCHELL, 2004). No entanto, ressalta-se que os bancos mostram pouco interesse no financiamento dessas empresas (CHONG; LU; ONGENA, 2013), alegando que esses negócios não geram recursos suficientes para pagamento e que não oferecem reais garantias que justifiquem a concessão do financiamento (KRAUTER; SOUSA; CASTANHEIRA, 2015).

Além disso, risco e custo são os principais entraves à concessão de serviços financeiros para negócios de pequeno e médio porte, uma vez que as instituições bancárias consideram arriscada e custosa a concessão de financiamento para esses empreendimentos, alegando posse de ativos insuficientes, baixa capitalização, vulnerabilidade ao mercado e falta de registros contábeis (NAGARAJU; VANI, 2013).

Em razão da expressividade das razões que limitam o financiamento de pequenos negócios, no próximo tópico discute-se sobre os fatores limitantes ao financiamento de micro, pequenas e médias empresas.

\subsection{FATORES LIMITANTES AO ACESSO DE LINHAS DE CRÉDITO E FINANCIAMENTO POR EMPRESAS PARTICIPANTES DE APL}

Tendo em vista a necessidade de apoio as empresas de pequeno porte, indicadas na constituição federal de 1998 (BRASIL, 1998) e no Estatuto da Microempresa (BRASIL, 2006), o governo brasileiro passou a promover um tratamento diferenciado para essas organizações, por meio do estreitamento e reforço das ações do Serviço Brasileiro de Apoio às Micro e Pequenas Empresas - SEBRAE, da criação do Ministério de Ciência e Tecnologia - MCT, e da abertura de novos meios de financiamento às empresas de menor porte (NARETTO; BOTELHO; MENDONÇA, 2004).

Contudo, ainda são incipientes os esforços ao apoio financeiro para essas empresas, levando-se em consideração que os bancos oferecem pouco suporte aos investimentos necessários para o setor empresarial, bem como são avessos a compartilhar os riscos dos negócios (CARVALHO; ABRAMOVAY, 2004). Outro fator preponderante nesse contexto, refere-se as políticas públicas do país, que apresentam barreiras que impactam negativamente no acesso ao crédito (AOKI; BADALOTTI, 2014).

Uma alternativa que é considerada na literatura, para que haja a superação desses entraves, refere-se a formação de arranjos de micro, pequenas e médias empresas. No entanto, essa articulação é pouco explicitada na literatura, principalmente na literatura internacional, que direciona seu foco para o financiamento de micro, pequenas e médias empresas de forma isolada (BRITTO; VARGAS; CASSIOLATO, 2001).

Mesmo com essa limitação, de acordo com Britto, Vargas e Cassiolato (2001, p. 6) "é possível avançar no sentido do estabelecimento de algumas conexões analíticas entre a conformação institucional dos esquemas de financiamento e as necessidades específicas de micro, pequenas e médias empresas integradas a arranjos e sistemas". Assim, tem-se que o apoio financeiro aos APLs é fundamental para o crescimento e consolidação desses arranjos (KACHBA; VAZ; HATAKEYAMA, 2009).

Ainda que não tratem diretamente de APLs, García-Tabuenca, Crespo-Espert e Cuadrado-Roura (2009) informam que as dificuldades e os custos do acesso ao crédito prejudicam a alavancagem financeira das empresas de menor porte, resultando em restrições econômicas, baixo desenvolvimento, redução de inovações e baixo número de empregos gerados. 
No tocante as limitações encontradas pelas pequenas e médias empresas no acesso a financiamento externo observam-se que algumas barreiras são destacadas na literatura. De acordo com Osei-Assibey, Bokpin e Twerefou (2012), as altas taxas associadas aos empréstimos, são fatores cruciais para o desincentivo do financiamento externo por parte das empresas de pequeno porte.

De modo semelhante, Sheng (2008) aponta que as principais barreiras à obtenção de financiamentos por pequenas empresas são a elevada taxa de juros, requisição de garantias e exigências de volumes financeiros e pagamentos no curto prazo.

Por essa razão, Tavares, Pacheco e Almeida (2015) e Carvalho e Abramovay (2004), ressaltam que é expressivo o número de empresas que encontram dificuldades no acesso a crédito bancário, devido aos altos custos do empréstimo, que são compostos pelas comissões e despesas cobradas, assim como, pelas altas taxas de juros praticadas diante de baixos limites de crédito.

Para Nkundabanyanga et al. (2014), o financiamento para pequenas e médias empresas (PMEs) é restrito, particularmente devido às garantias insuficientes e a inexistência de um bom histórico de crédito nesses negócios. Outro fator de restrição evidenciado por Carey e Flynn (2005) é a falta de competência e conhecimento que essas empresas apresentaram em analisar e aplicar estrategicamente as informações necessárias para a captação de fontes mais baratas de financiamento.

Em síntese, as pequenas e médias empresas, participantes ou não de APLs, enfrentam problemas semelhantes na obtenção de financiamentos externos, os quais podem ser resumidos em: ausência de garantias; falta de registros contábeis; falta de capacitação dos empresários; níveis elevados de informalidade; definições de diretrizes por indivíduos distantes da realidade do arranjo; inadimplência; imagem negativa do setor, entre outros (BRITTO; VARGAS; CASSIOLATO, 2001; CARVALHO, 2005).

\section{PROCEDIMENTOS METODOLÓGICOS}

Diante da variedade de classificações metodológicas que pode ser atribuída a uma pesquisa, esse estudo classificou seus procedimentos quanto a abordagem, objetivos, procedimentos técnicos, instrumento para coleta de dados e técnica para análise das evidências (FONTELLES et al., 2009).

Dessa forma, no que se refere a forma de abordagem, foi realizado um estudo qualitativo, adequado para adquirir em profundidade a compreensão de um dado fenômeno (CORBIN; STRAUSS, 2008). Quanto aos objetivos, trata-se de uma pesquisa descritiva que buscou descrever determinado fenômeno - financiamento externo em APL - com o intuito de aprofundar a compreensão sobre a realidade estudada (BIROCHI, 2017).

O método adotado foi o estudo de caso único integrado, que de acordo com Yin (2010) é caracterizado pela existência de mais de uma unidade de análise em um único caso. Lobler, Lenhart e Avelino (2014) acrescentam que no caso único integrado a atenção é dirigida a uma ou mais subunidades, permitindo uma melhor compreensão do fenômeno estudado, tornando os resultados obtidos mais robustos e convincentes.

Nesse contexto, para essa pesquisa foram analisadas duas empresas participantes do APL de móveis da cidade de Maceió/AL. Além disso, analisou-se a percepção do órgão gestor do APL, representado pela Secretaria de Estado do Desenvolvimento Econômico e Turismo de Alagoas (SEDETUR/AL), em parceria com o Serviço Brasileiro de Apoio às Micro e Pequenas Empresas- SEBRAE. A descrição das subunidades de análise dessa pesquisa está apresentada no tópico 3.1 desse trabalho.

Dentre as razões para seleção do APL de móveis de Maceió como caso para esse estudo, justifica-se que, apesar de possuir poucos anos de formação, o APL vem ganhando destaque no 
cenário nacional, por meio da participação em eventos nacionais e internacionais, como por exemplo, as atuações na $6^{\text {a }}$ edição do Congresso Nacional Moveleiro, em Curitiba, e no salão internacional do móvel em Milão, respectivamente, servindo como referência para outros arranjos produtivos do país (AGÊNCIA ALAGOAS, 2018).

Além disso, o APL de móveis de Maceió vem se destacando por sua organização, com a venda de diversos produtos (incluindo produtos sofisticados) para diferentes mercados, bem como por meio de seus crescentes índices de comercialização e produção (AGÊNCIA ALAGOAS, 2018). Nesse contexto, salienta-se a necessidade e relevância de um suporte financeiro, para o desenvolvimento das empresas participantes desse arranjo produtivo.

Quanto às fontes de evidências, foi utilizado um roteiro de entrevista semiestruturado, aplicado aos gestores de duas empresas participantes do APL e também a gerente do APL, representante da SEDETUR e do SEBRAE na coordenação do arranjo produtivo. O roteiro de entrevista foi baseado em uma única categoria de análise, cujos elementos estão apresentados no Quadro 1.

Quadro 1: Categoria e elementos de análise

\begin{tabular}{|l|r|}
\hline Categoria & Elemento de análise \\
\hline Financiamento externo & $\begin{array}{l}\text { - Barreiras para prospectar financiamentos externos. } \\
\end{array}$ \\
& - Fatores limitantes no acesso a crédito externo. \\
& Apoio do APL na obtenção de financiamentos. \\
\hline
\end{tabular}

Fonte: Elaborado pelos autores (2021)

A fim de preservar a identidade das organizações participantes da pesquisa, elas receberam a nomeação fíctícia de empresas A, B e organização C (gestora do APL), representados, respectivamente, pelos entrevistados A, B e C.

A análise dos dados foi realizada de acordo com as etapas de seleção, codificação, tabulação, análise e interpretação, propostas por Birochi (2017) e resumidas no Quadro 2.

Quadro 2: Procedimentos de análise dos dados

\begin{tabular}{|l|l|}
\hline Etapa & Procedimento \\
\hline Seleção & $\begin{array}{l}\text { As evidências obtidas foram inicialmente verificadas a fim de detectar falhas de } \\
\text { descrição dos relatos dos entrevistados. }\end{array}$ \\
\hline Codificação & $\begin{array}{l}\text { Frases, sentenças e parágrafos foram destacados e associados às temáticas em estudo, } \\
\text { especificamente APL e financiamento externo. }\end{array}$ \\
\hline Tabulação & $\begin{array}{l}\text { Os dados foram ordenados em quadros para facilitar a visualização e comparação } \\
\text { pelos pesquisadores. }\end{array}$ \\
\hline Análise & $\begin{array}{l}\text { Os dados foram analisados conforme a literatura consultada sobre financiamento em } \\
\text { APLS. }\end{array}$ \\
\hline Interpretação & $\begin{array}{l}\text { Os dados foram interpretados, de forma conjunta, com inferências e percepções dos } \\
\text { pesquisadores. }\end{array}$ \\
\hline
\end{tabular}

Fonte: Elaborado pelos autores a partir de Birochi (2017)

\subsection{UNIDADES DE ANÁLISE}

A empresa A, fundada no ano de 2005, trabalha com móveis, artes e decoração. Nessa empresa a entrevista foi concedida pela fundadora e gestora do negócio (entrevistada A). A empresa B, por sua vez, foi fundada em 2011, trabalha com móveis e estofados. Nessa firma, a entrevista foi realizada com o proprietário e atual gestor da empresa (entrevistado B). Acrescenta-se que as empresas A e B fazem parte do APL desde sua formalização, no ano de 2013, uma vez que ambas, já participavam do programa Procompi, um programa de apoio a competitividade as empresas de pequeno porte. 
A organização C é a Secretaria de Estado do Desenvolvimento Econômico e Turismo (SEDETUR/AL), que dispõe de uma área administrativa específica para o gerenciamento de APLs em Alagoas. Nessa instituição a entrevista foi realizada com a gerente do APL (entrevistada $\mathrm{C}$ ), responsável por coordenar as atividades desse arranjo produtivo.

\section{DISCUSSÃO E ANÁLISE DOS DADOS}

A fim de facilitar a compreensão dos resultados obtidos nessa pesquisa, estes são, inicialmente, apresentados conforme os elementos de análise apresentados no Quadro 1 barreiras para prospectar financiamentos externos, fatores limitantes no acesso a crédito externo e apoio do APL na obtenção de financiamentos; e posteriormente analisados e comparados a literatura.

\subsection{BARREIRAS PARA PROSPECTAR APOIO FINANCEIRO EXTERNO}

Os participantes empresariais da pesquisa foram inicialmente questionados sobre as barreiras para obtenção de financiamentos para o desenvolvimento de seus respectivos negócios. Levando-se em consideração que os empreendedores atuaram de maneira informal por alguns anos, foi possível indagá-los, quanto ao financiamento externo antes e depois da formalização de suas empresas.

Sobre esse assunto, a entrevistada A contou que:

A informalidade é como você não ter carteira de identidade. Você não é um cidadão, não existe; então como é que você vai crescer. A empresa não consegue pegar: empréstimo, crédito com o fornecedor, crédito no mercado, fazer parceria, enfim, não consegue fazer nada [...] Senti a necessidade de buscar crédito na época que eu não tinha inscrição no CNPJ, mas não busquei, pois eu sabia que seria negado. Eu senti necessidade de um capital de giro, de um capital para começar o negócio, mas eu não busquei nenhum, nem com a família, nem em banco, nem em lugar algum (ENTREVISTADA A).

No que se refere às barreiras antes e após a formalização, o entrevistado B afirmou que:

Quando você formaliza a empresa, novas portas e novos horizontes se abrem. Antes de formalizar eu tentei um empréstimo, mas eles não emprestaram, e para pessoa física o financiamento sai muito caro. Se você pega um empréstimo pessoa física, fica muito caro, e você fica sem competitividade. Ainda bem que eu não consegui! (ENTREVISTADO B).

Complementando suas percepções sobre as barreiras no acesso ao financiamento externo, a entrevistada A explicou que:

Tem um velho ditado que diz: banco só empresta dinheiro a quem tem dinheiro [...] quanto mais dinheiro você tem, mais o banco se aproxima, nem precisa você pedir, ele já te oferece, já liga para você, perguntando se você quer dobrar seu patrimônio [...] agora para você pequeno empresário que está crescendo, que está querendo um lugar ao sol, só restam as portas fechadas (ENTREVISTADA A).

E continuou:

A taxa é muito elevada, a taxa bancária é desumana [...] o que é que o banco 
faz: eu te empresto, mas você será penalizado porque está precisando de recursos hoje, e isso muitas vezes, não permite que o empresário, faça o que ele deveria fazer com o valor que captou (ENTREVISTADA A).

De modo semelhante, o entrevistado B contou que:

O crédito bancário é parecido entre as instituições disponíveis, faz lembrar carro, só muda mesmo uma taxinha ali, uma taxinha acolá. Nós sabemos que se você for pegar um crédito de capital de giro de, por exemplo, 50 mil, você vai verificar que as condições ficam quase as mesmas, só muda o nome do banco (ENTREVISTADO B).

O entrevistado complementou explicando que:

As taxas são altas, são altíssimas e agora com toda a crise é que estão altas mesmo. Ainda assim eu pretendo pegar o financiamento, por que as taxas dos financiamentos específicos para o APL são menores do que qualquer outro recurso a que eu venha adquirir em forma de empréstimo (ENTREVISTADO B).

Por outro lado, a entrevistada C (gerente do APL) apresentou posicionamento divergente dos empresários, informando inclusive que não há falta de crédito para o setor moveleiro. Ela disse que:

Eu acho que até tem crédito para o setor moveleiro. Por exemplo, a Caixa Econômica tem linhas específicas de crédito para o setor. Ela tem o MoveisCard, o ConstruCard, e o Minha Casa Melhor, que foi lançado ano passado [...] o MoveisCard é específico para financiar empresas do setor de móveis.

Sobre a taxa de juros, a entrevistada $\mathrm{C}$ novamente discorda dos entrevistados explicando que:

As taxas de juros são diferenciadas para empresas pertencentes ao APL, são taxas menores do que a do mercado convencional [...] eu promovi um workshop de acesso ao crédito em 2014 e levei cinco bancos: Banco do Nordeste, Caixa, Banco do Brasil, Desenvolve e BNDES [...] a dificuldade do BNDES foi a exigência da regularização ambiental, apesar de ele ter uma taxa boa de juros. [...] As taxas do Banco do Nordeste hoje são consideradas as melhores pelos empresários, sendo que a burocracia é muito grande.

Sobre as barreiras para obtenção de financiamento pelas empresas participantes do APL, a entrevistada $\mathrm{C}$ comentou que as barreiras ao crédito também ocorrem devido a inadimplência das empresas, e aos processos ineficientes das instituições financeiras. No entanto, "as empresas de médio porte ou as que já possuem um relacionamento com as instituições financeiras, dispõem de maior facilidade de liberação do crédito" (ENTREVISTADA C). Essa entrevistada também comentou que a falta de controle gerencial também cria barreiras as empresas do APL, inclusive porque muitas delas apresentam dificuldades em divulgar dados financeiros.

\subsection{FATORES LIMITANTES NO ACESSO A CRÉDITO EXTERNO}

No que se refere aos fatores limitantes, que embora não sejam tão incisivos quanto às barreiras, mas que ainda assim dificultam a obtenção de financiamentos, a entrevistada A explicou que: 
O principal entrave com certeza é a questão da garantia, não tenha dúvida [...] Qual é a garantia que você tem? Geralmente um pequeno empresário está de aluguel, e mesmo que o espaço físico do empreendimento seja dele, não pode ser dado como garantia, por que a justiça não pode tomar. Um carro, também não é garantia, o banco não aceita. $\mathrm{O}$ banco quer que você tenha como garantia um imóvel [...] é completamente incongruente com a realidade do pequeno negócio (ENTREVISTADA A).

Ela ainda acrescentou que:

De uma forma geral os microempresários estão despreparados para tudo [...] Tem empresário que simplesmente não quer o empréstimo por que tem medo de pegar o empréstimo; e o pior de tudo é quando ele pega um empréstimo que não foi planejado centavo por centavo o que será feito com o dinheiro. Por que, se você pega empréstimo para pagar dívidas, é o mesmo que trocar seis por meia dúzia, e é o que acontece muita gente faz isso e continua no buraco (ENTREVISTADA A).

Por outro lado, a entrevistada A reconhece que o relacionamento e comportamento de outras instituições financeiras é diferentes, especialmente com a agência de fomento Desenvolve Alagoas que tem auxiliado o APL. Ela contou que:

No final do ano passado, a gerente do APL nos informou que a Desenvolve lançou um produto com juros baixos para pequenos empreendedores. Foi quando eu fui e tive uma boa surpresa, pois realmente eles tinham modificado o processo, e agora eles têm um plano, que se você é empresário e está participando de algum APL, você tem uma taxa diferenciada, e a partir daí eu percebi uma condição melhor para a empresa (ENTREVISTADA A).

Em complemento a essa discussão, a entrevistada abordou também a questão da carência para pagamento de parcelas de empréstimos e outras modalidades de financiamento, ela contou que:

Qualquer micro empresário espera do banco uma carência, que é tão importante quanto à taxa de juros. A maioria dos bancos não oferece carência, nem mesmo o BNDES. Quer dizer, se você está fazendo um empréstimo é por que você precisa de um recurso extra para colocar o negócio para frente, então como é que você pede $\mathrm{X}$ hoje, e no final do mês você já vai ter de pagar a primeira parcela, se você nem conseguiu fazer alguma coisa com o recurso captado. Então uma coisa que eu nunca entendi é essa dificuldade em nos conceder carência.

E reforçou mais uma vez o papel de instituições de fomento direcionadas ao desenvolvimento de pequenos negócios em APL, explicando que "Já nesse plano da Desenvolve [agência de fomento] além dos juros mais baixos tem a questão da carência de seis meses, para quem faz parte de APLs (ENTREVISTADA A). Percepção corroborada pela entrevistada $\mathrm{C}$ que também acredita que "a agencia de fomento é menos burocrática e não demora".

Ainda sobre os fatores limitantes a procura e obtenção de financiamentos, o entrevistado B comentou que:

Eu acho que a exigência de garantias é um dos principais gargalos para quem vai pegar empréstimo bancário [...] todo o empresário fica com medo de penhorar um bem, e lá na frente acontecer um imprevisto e ter seu bem 
tomado, pois o banco não perdoa, ele quer o dinheiro de volta a qualquer custo (ENTREVISTADO B).

Ele também acredita que o despreparo em gestão dos empresários também é um fator limitante. Sobre isso ele disse:

Os empresários que não buscam as informações, por que nós fazemos o planejamento das atividades do APL no início do ano e diante dessas informações, cada empresário diz o que vai querer para a sua empresa [...] também tem desconhecimento dos empresários por parte dos produtos financeiros (ENTREVISTADO B).

Os entrevistados apontaram também os procedimentos administrativos das instituições financeiras como possíveis limitantes na busca por financiamentos externos, contudo, eles possuem percepções diferentes, pois o entrevistado B considera que há demora na liberação ao crédito, ocasionando até na falta de interesse pelo financiamento. A entrevistada A, por sua vez, não percebe essa demora, uma vez que suas experiências anteriores ocorreram sem retardamento, já que possui relação de longa data com o banco o qual foi feita a transação financeira.

\subsection{APOIO DO APL PARA OBTENÇÃO DE FINANCIAMENTOS EXTERNOS}

Sobre o apoio do APL na obtenção de financiamentos externos, percebeu-se que a coordenação do arranjo promove o apoio por meio de reuniões entre empresários e representantes do setor financeiro. Sobre esse assunto, o entrevistado B contou que:

Sempre é tocado no assunto de financiamento, a gente sempre se reúne com os bancos. Já teve rodada de informações com vários bancos de uma só vez, como com o Banco do Brasil, Caixa, BNDES, Banco do Nordeste, e a Desenvolve-AL, que é uma agência de fomento do estado. Cada banco diz o que tem a oferecer para as empresas, e cabe as empresas estar apta a pegar o devido crédito (ENTREVISTADO B).

Sobre essa interação com instituições financeiras, a entrevistada $\mathrm{C}$ acrescentou que mesmo diante dos frequentes contatos, ainda existem barreiras. Ela disse que:

um crédito que as empresas ainda não têm é para o financiamento da sede própria, e eu ainda não vi um crédito que agradasse as empresas, nesse sentido. O Banco do Brasil até disponibilizou crédito desse tipo uma vez, mas a burocracia foi muito grande, o que gerou desinteresse [...] Essa linha de crédito seria interessante, por que a maioria das empresas paga aluguel de no mínimo dois mil e quinhentos reais [...] no lugar de pagar aluguel eles poderiam pagar algo que seria deles. Essa linha de crédito seria positiva, e a procura seria grande.

Para que o apoio do APL se consolide e ofereça suporte as empresas participantes, a entrevistada $\mathrm{C}$ destaca a importância de participação nas reuniões e convenções do arranjo. Ela explica que:

As empresas que são mais frequentes nas reuniões, têm prioridade nas ações propostas. Tem empresa que é do APL, e não sabe, quer dizer, saber sabe, que a gente informa por e-mail, mas não lê as informações passadas, que eles sendo do APL tem taxas de juros diferenciadas. Assim, deve ter empresas que nem sabem que possuem 
taxas diferenciadas por serem do APL, por que não se informam e não participam das reuniões (ENTREVISTADA C).

A entrevistada $\mathrm{C}$ reforça a importância de integração ao grupo por parte das empresas participantes do APL explicando que "os empresários que não participam do grupo, e que não participam das reuniões ficam buscando linha de crédito por outros meios e acabam perdendo a oportunidade de ter uma linha de crédito que foi conquistada para o setor".

No tocante a participação nas reuniões, convenções e capacitações promovidas pela gerência do APL, a entrevista C argumenta que: "existe uma mudança de comportamento quando os empresários participam de capacitações, eles ficam com uma visão mais aberta, com conhecimento mais amplo e quem participa pouco tem uma visão fechada".

No tocante a novas ações de apoio ao acesso de financiamentos externos, a entrevistada C explicou que:

Eu participei de um workshop do Banco do Nordeste, acerca de um seminário de investimento. Eles fizeram uma prospecção em que setores deveriam investir e o governo do estado indicou o setor moveleiro. Então esse ano eles devem nos procurar. Eles sempre fazem esse tipo de estudo.

A partir desse workshop e da indicação do governo do Estado, a entrevistada acredita que novas ações e suporte no acesso a crédito serão desenvolvidas e tornadas disponíveis às empresas participantes do APL de móveis de Maceió.

\subsection{ANÁLISE DOS RESULTADOS}

Os principais achados da pesquisa, apresentados no tópico anterior, estão sintetizados no Quadro 3 e discutidos a seguir.

Quadro 3 - Principais resultados da pesquisa

\begin{tabular}{|c|c|c|}
\hline $\begin{array}{l}\text { Barreiras para } \\
\text { prospectar apoio } \\
\text { financeiro externo }\end{array}$ & Fatores limitantes & $\begin{array}{l}\text { Apoio do APL para } \\
\text { obtenção de } \\
\text { financiamentos }\end{array}$ \\
\hline $\begin{array}{ll}\text { - } & \text { Informalidade } \\
\text { - } & \text { Tamanho do negócio } \\
\text { - } & \text { Altas taxas de juros } \\
\text { - } & \text { Inadimplência }\end{array}$ & $\begin{array}{ll}\text { - } & \text { Oferecimento de garantias } \\
\text { - } & \text { Prazos de carência } \\
\text { - } & \text { Ausência de gestão } \\
\text { profissionalizada } \\
\text { - } & \text { Procedimentos administrativos } \\
& \text { e burocráticos das instituições } \\
& \text { financeiras }\end{array}$ & $\begin{array}{l}\text { - Reuniões e encontros com } \\
\text { instituições financeiras. } \\
\text { - Busca ne novas } \\
\text { modalidades de } \\
\text { financiamento (sede } \\
\text { própria). }\end{array}$ \\
\hline
\end{tabular}

Fonte: Elaborado pelos autores (2021)

Diante dos resultados obtidos percebeu-se que o apoio financeiro as empresas formalizadas ocorre com menos entraves se comparado as empresas não formalizadas. Na visão dos empreendedores, é praticamente impossível obter qualquer tipo de crédito e crescimento sem a formalização do empreendimento. Essa constatação é reforçada por Zylfijajas e Nikoloski (2016) que constataram que as empresas informais têm lacunas significativas em informações, credibilidade e habilidades necessárias para acessar o financiamento externo, e por essa razão enfrentam maiores obstáculos do que as empresas formais.

Os empreendedores relataram que percebem crédito reduzido e poucas opções de financiamento para os pequenos negócios e que, devido as altas taxas de juros praticadas, as linhas tradicionais de financiamento se tornam quase inacessíveis a essas empresas. Sobre esse 
assunto, Soki (2019) informa que as altas taxas de juros são o principal obstáculo ao acesso das pequenas e médias empresas brasileiras a empréstimos e linhas de crédito, além de provocar uma forte desmotivação aos pequenos empresários.

A inadimplência foi um fator desencadeador de barreiras a novos financiamentos, conforme percepção da gerente do APL e relatos de dificuldades para honrar parcelas de empréstimos. Nesse contexto, manter-se sem restrições comerciais e com bons serviços contábeis é fundamental para o acesso ao crédito (BRITTO; VARGAS; CASSIOLATO, 2001; CARVALHO, 2005).

Quanto aos fatores limitantes, um ponto convergente entre a visão da gestora do APL e das empresas inseridas neste, diz respeito a falta de competências necessárias e a falta de interesse das empresas participantes do APL em buscar informações. Esses fatores são preponderantes para que o financiamento externo seja mal sucedido, já que, ou os empresários desconhecem os serviços com melhores condições para sua empresa ou não buscam as informações disponíveis para as negociações financeiras (BRITTO; VARGAS; CASSIOLATO, 2001; CAREY; FLYNN, 2005; AOKI; BADALOTTI, 2014).

Além disso, percebe-se que as barreiras à obtenção de financiamento são também resultantes da falta de gestão profissionalizada nesses negócios. Nesse sentido, Dini (2010) defende que as empresas em aglomerações e redes de cooperação necessitam estabelecer programas de gestão profissionalizada.

A exigência de garantia foi também um fator limitante a obtenção de financiamentos pelas empresas do APL. O Sebrae (2014) destaca que a ausência de garantias sólidas é um dos principais motivos de recusa de crédito aos pequenos empreendimentos, que por essa razão devem buscar o apoio de programas como o Fundo de Aval da Micro e Pequena Empresa (CNI, 2020) e as Sociedades de Garantias de Crédito (SGC) (ABREU; ZOTES, 2018).

Adicionalmente, ao relatar que os procedimentos administrativos das instituições financeiras é um limitante a busca e obtenção de financiamentos, a percepção dos entrevistados corrobora os achados de Soki (2019), de que as altas taxas de juros, o alto custo burocrático, a vasta documentação e histórico de crédito requeridos nas operações bancárias afastam os pequenos empresários dessa alternativa de financiamento para suas atividades produtivas.

Nesse contexto, considerando que a Desenvolve Alagoas (instituição de fomento) oferece condições diferenciadas para o financiamento de empresas participantes de APL, se torna ainda mais importante que essas empresas conheçam os programas institucionais de fomento aos arranjos produtivos (OLIVEIRA et al., 2017).

No tocante ao apoio fornecido pelo APL, destaca-se que embora a promoção de reuniões e divulgação de alternativas de financiamento sejam iniciativas valoráveis, é necessário que a gestão do APL se envolva também na elaboração de planos de desenvolvimento e políticas públicas que ampliem a atuação, interação e alcance de resultados das empresas inseridas nesses arranjos (ROCHA; OLAVE, 2019).

\section{CONCLUSÕES}

Os resultados obtidos nessa pesquisa demonstram que as empresas participantes do APL de móveis de Maceió enfrentam dificuldades no acesso a recursos financeiros externos. Nesse sentido, constatou-se que as restrições de crédito ao APL de móveis ocorrem principalmente devido as garantias exigidas pelas instituições financeiras, a inadimplência, a falta de informações gerenciais, a formalização das empresas, as altas taxas de juros praticadas no mercado, ao crédito reduzido, e a falta de interesse dos empresários em buscar as informações necessárias e disponíveis.

Além disso, percebeu-se uma certa limitação nas opções financeiras oferecidas ao APL que nem sempre atendem as necessidades e expectativas de seus participantes, a exemplo da 
inexistência de uma linha de crédito para aquisição de sede própria para as empresas. Por outro lado, ficou evidenciada a importância de instituições de fomento, a exemplo da Desenvolve Alagoas, que proporciona as melhores condições na concessão de carência para pagamentos e cobra menores taxas que os bancos convencionais.

Em razão dos resultados obtidos, sugere-se que novas pesquisas analisem o processo e limitadores do financiamento externo em outros APLs da região nordeste e do Brasil, a fim de comparar com os resultados apresentados nesse estudo. Além disso, novos estudos podem identificar se APLs de diferentes naturezas comerciais apresentam distinções no acesso a crédito externo e o quanto a maturidade desses arranjos influencia nos processos de financiamento.

Considerando o entendimento de que o financiamento externo é preponderante ao desenvolvimentos de pequenos negócios, inclusive das empresas participantes de APLs, este trabalho alcançou seu objetivo, pois conseguiu melhor compreender como ocorre o acesso a financiamentos externos por empresas em APLs, assim como categorizar as dificuldades desse processo em barreiras, fatores limitantes e ações de apoio.

Dessa forma, os resultados apresentados podem ser úteis aos órgãos gestores de APLs e também aos formuladores de políticas públicas como caminhos para construção de soluções às dificuldades de financiamento enfrentadas por pequenas empresas inseridas em arranjos produtivos.

Além disso, em razão das barreiras e limitações no acesso a financiamento pelas pequenas e médias empresas participantes de APLs (CARVALHO, 2005), assim como em consideração a variedade de benefícios proporcionados aos negócios inseridos nesses arranjos (ROCHA; OLAVE, 2019), fica evidente a necessidade de criar mecanismos sociais, empresariais e políticos que estimulem a concessão de crédito a esses negócios e fomentem, conjuntamente, o desenvolvimento produtivo, comercial e empresarial de empresas e arranjos produtivos locais. 


\section{REFERÊNCIAS}

ABREU, W. R. A.; ZOTES, L. P. Sociedades de garantia de crédito: estudo comparativo dos modelos de Brasil, Chile, Espanha e Portugal. In: Congresso Internacional de Administração, 2018, Sucre, Bolívia. Anais... Sucre, 2018.

AGÊNCIA ALAGOAS. APL Móveis em Maceió e Entorno [SHP], 2018. Disponível em: < https://bityli.com/bqFG0 >. Acesso em: 18 jul. 2021.

AGÊNCIA ALAGOAS. APL APL Móveis Maceió e Entorno expõem produtos em Salão Internacional, em Milão, 2017. Disponível em: < https://bityli.com/LnSb3>. Acesso em: 18 jul. 2021.

AOKI, V. C. G.; BADALOTTI, R. M. Dificuldades e perspectivas no acesso de micro e pequenas empresas a linhas de crédito públicas: o caso de Chapecó. Revista de Administração Pública, v. 48, n. 5, p. 1305-1327, set./out. 2014.

BIROCHI, R. Metodologia de estudo e de pesquisa em administração. Florianópolis : Departamento de Ciências da Administração/UFSC, 2017.

BRITTO, J.; VARGAS, M.; CASSIOLATO, J. E. Formatos Organizacionais para Financiamento de Arranjos e Sistemas de MPME - NT9, 2001. Disponível em: < https://bityli.com/hKkfI >. Acesso em: 13 jan. 2021.

BURGER, P. Comparison of the Financing Structure of Industrial Clusters and Service Clusters in the World. Journal of Applied Economic Sciences (JAES), v. 13, n. 60, p. 1581-1592, 2018.

CARDOSO, U. C.; CARNEIRO, V. L. N.; RODRIGUES, E. R. Q. APL: arranjo produtivo local. Brasília : Sebrae, 2014.

CAREY, D.; FLYNN, A. Is bank finance the Achilles' heel of Irish SMEs? Journal of European Industrial Training, v. 29, n. 9, p. 712-729, 2005.

CARVALHO, C. E.; ABRAMOVAY, R. O difícil e custoso acesso ao sistema financeiro. In SANTOS, Carlos Alberto dos, org. (2004) - Sistema Financeiro e as micro e pequenas empresas - Diagnósticos e perspectivas - SEBRAE - Brasília p. 17-45, 2004.

CARVALHO, M. A. D. de. Instrumentos de apoio financeiro específicos a empresas localizadas em arranjos produtivos locais: um estudo de caso do APL de Nova Friburgo. 2010. Dissertação (Mestrado) - Mestrado Acadêmico em Administração Pública, Fundação Getulio Vargas, Rio de Janeiro, 2005.

CERBUSCA, V. Financing SME future development. Theoretical and Scientifical Journal, 2015.

CHONG, T. T.L.; LU, L.; ONGENA, S. Does banking competition alleviate or worsen credit constraints faced by small- and medium-sized enterprises? Evidence from China. Journal of Banking \& Finance, v. 37, p. 3412-3424, 2013.

CNI - Confederação Nacional da Indústria. Crédito com uso do fundo de Aval às Micro e Pequenas Empresas: Como as micro e pequenas empresas podem se beneficiar. Disponível em: <https://bityli.com/19Szs $>$. Acesso em: 18 jul. 2021.

CORBIN, J.; STRAUSS, A. Basics of Qualitative Research: Techniques and Procedures for Developing Grounded Theory. $3^{\text {a }}$ Edição. Thousand Oaks, CA: Sage, 2008.

DEGRYSE, H.; MASSCHELEIN, N.; MITCHELL, J. SMEs and Bank Lending Relationships: the Impact of Mergers. National Bank of Belgium Conference, n. 46, may, 2004.

DINI, M. Competitividad, redes de empresas y cooperación empresarial. Santiago: Instituto 
Latinoamericano de Planificación Económica y Social (ILPES), 2010.

FERREIRA, M. T. DA S.; MEIRELES, S. S. DE; MACEDO, M. A. DA S.; BARONE, F. M.; SANT'ANNA, P. R. DE; ZOTES, L. P. Análise do desenvolvimento de Arranjos Produtivos Locais (APLs): um estudo de caso do município de Paraty (RJ). Revista de Administração Pública, v. 45, n. 2, p. 517-539, mar./abr. 2011.

FONTELLES, M. J.; SIMÕES, M. G.; FARIAS, S. H.; FONTELLES, R. G. S. Metodologia da pesquisa científica: Diretrizes para a elaboração de um protocolo de pesquisa. Revista Paraense de Medicina, v. 23, n. 3, 2009.

GARCÍA-TABUENCA, A.; CRESPO-ESPERT, J. L.; CUADRADO-ROURA, J. R. Public financing and entrepreneurship: behaviour and regional heterogeneity of SMEs. Investigaciones Regionales, p. 89-109, 2009.

HERR, H.; NETTEKOVEN, Z. M. The Role of Small and Medium-sized Enterprises in Development What Can be Learned from the German Experience? Berlim: Friedrich Ebert Stifung, 2017.

HUSSAIN, J.; MILLMAN, C.; MATLAY, H. SME financing in the UK and in China: a comparative perspective. Journal of Small Business and Enterprise Development, v. 13, n. 4, p. $584-599,2006$.

KACHBA, Y. R.; VAZ, C. R.; HATAKEYAMA, K. Mapeamento de investimento financeiro dos APLs do estado do Paraná: um estudo multicaso para análise de execução das ações estratégicas. In: XXIX Encontro Nacional de Engenharia de Produção - ENEGEP, Salvador 2009. Anais... ENEGEP, 2009.

KRAUTER, E.; SOUZA, A. F.; CASTANHEIRA, D. R. F. As micro, pequenas e médias empresas e o financiamento bancário. In: CONGRESSO UFABC DE EMPREENDEDORISMO, 2015, São Paulo. Anais... Congresso UFABC de Empreendedorismo, 2015.

LASTRES, H. M. M.; CASSIOLATO, J. E. Glossário de Arranjos e Sistemas Produtivos e Inovativos Locais. Rede de Pesquisa em Sistemas Produtivos e Inovativos Locais (Redesist), Rio de Janeiro, nov. 2003. Disponível em: $<$ http://www.mdic.gov.br//arquivos/dwnl_1289323549.pdf>. Acesso em: 12 jan. 2016.

LÖBLER, M. L.; LEHNHART, E. R.; AVELINO, A. F. A. Como estão sendo Conduzidos os Estudos De Caso? Uma Reflexão Sobre os Trabalhos Publicados na Área de Administração. In: XXXVIII Encontro da ANPAD, 2014, Rio de Janeiro. Anais... Rio de Janeiro, 2014.

MARTINS, D. M.; FARIA, A. C. De; FARINA, M. C. Cooperação e poder na qualidade do relacionamento das cooperativas de crédito. R. Adm. FACES Journal Belo Horizonte, v. 15 n. 2 p. 25-45 abr./jun. 2016.

MOHAMAD, M. R. et al. Financial access for starting a business: Evidence of internal and external financial sources, and performance of Malaysian SMEs. Journal of Entrepreneurship and Business, v. 3, n. 1, p. 1-16, 2015.

MUELLER, E. F.; JUNGWIRTH, C. Are cooperative firms more agile? A contingency perspective on small and medium-sized enterprises in agglomerations and peripheral areas. Small Business Economics, 2020.

NAGARAJU, B.; VANI S.D, K. Problems and prospects in bank SME financing in Índia. Indian Streams Research Journal, v. 3, n. 2, mar. 2013.

NARETTO, N.; BOTELHO, M. DOS R.; MENDONÇA, M. A trajetória das políticas públicas para pequenas e médias empresas no Brasil: do apoio individual ao apoio a empresas articuladas 
em arranjos produtivos locais. Planejamento e Políticas Públicas, n. 27, 2004.

NKUNDABANYANGA, S. T.; KASOZI, D.; NALUKENGE, I.; TAURINGANA, V. Lending terms, financial literacy and formal credit accessibility. International Journal of Social Economics, v. 41, n. 5, p. $342-361,2014$.

OLIVEIRA, C. W. A.; COSTA, J. A. V.; Figueiredo, G. M.; Moraes, A. R.; Carneiro, R. B.; Silva, I. B. Arranjos produtivos locais e desenvolvimento. Rio de Janeiro: Ipea, 2017.

OSEI-ASSIBEY, E.; BOKPIN, G. A.; TWEREFOU, D. K. Microenterprise financing preference: Testing POH within the context of Ghana's rural financial market. Journal of Economic Studies, v. 39, n. 1, p. 84-105, 2012.

REVZON, O. A ; POCHEKUTOV, M. P.; AKSYONOVA, T. Sources of Innovation Financing in Industrial Clusters. Rússia: Springer International Publishing, 2021.

ROCHA, R. O. R ; OLAVE, M. E. L. Cooperação e aprendizado interorganizacional pelo uso de redes sociais digitais: uma análise no arranjo produtivo local (APL) de tecnologia da informação em Aracaju/SE. REUNA, v. 24, n. 3, p. 20-40, 2 nov. 2019.

SEBRAE. Conheça opções de garantia de crédito para pequenos negócios, 2014. Disponível em: $<$ https://bityli.com/eJEGa $>$. Acesso em: 18 jul. 2021.

SEBRAE. Financiamento dos pequenos negócios no Brasil, 2015. Disponível em: < http://www.bibliotecas.sebrae.com.br/chronus/ARQUIVOS_CHRONUS/bds/bds.nsf/c3f8192f d449605b9a45b7ebc68196ae/\$File/5789.pdf>. Acesso em: 18 jul. 2021.

SEBRAE. O financiamento das MPE no Brasil, 2017. Disponível em: < https://bibliotecas.sebrae.com.br/chronus/ARQUIVOS_CHRONUS/bds/bds.nsf/843a3cb8bd1 901b9dec713eb3cdbb260/\$File/7754.pdf/>. Acesso em: 18 jul. 2021.

SEBRAE. Participação das MPE na economia nacional e regional, 2020. Disponível em: $<$ https://datasebrae.com.br/documentos/>. Acesso em: 18 jul. 2021.

SHENG, H. H. Modelos de financiamento baseados em relaçőes pessoais: experiência de empreendedores chineses no Brasil. Revista de Administração Contemporânea, v. 12, n. 3, p. 741-761, jul./set. 2008.

SIMONETTI, E. R. S; KAMIMURA, Q. P; OLIVEIRA, E. P. A. Q. As políticas públicas direcionadas ao desenvolvimento de arranjos produtivos locais. Latin American Journal of Business Management, [S.1.], v. 6, n. 1, 2015.

SOKI, E. A. Mercado de crédito para MPES - falhas e fintechs. 2019. 107 f. Dissertação (Mestrado em Governança e Desenvolvimento) - Escola Nacional de Administração Pública, Brasília, 2019.

TAVARES, F. O.; PACHECO, L.; ALMEIDA, E. F. Financiamento das pequenas e médias empresas: análise das empresas do distrito do Porto em Portugal. Revista de Administração, São Paulo, v. 50, n. 2, p. 254-267, abr./maio/jun. 2015.

TIZZIOTTI, C. P. P.; TRUZZI, O. M. S.; BARBOSA, A. S. Arranjos produtivos locais: uma análise baseada na participação das organizações locais para o desenvolvimento. Gestão \& Produção, v. 26, n. 2, 2019.

URBANČÍKOVÁ, N. ; BURGER, P. CENTRALISED OR DECENTRALISED PUBLIC FINANCING OF CLUSTERS. Journal of Business Economics and Management, v. 17, n. 2, p. 267-282, 2016.

VERSCHOORE, J. R.; BALESTRIN, A. Ganhos competitivos das empresas em redes de cooperação. R. Administração - Eletrônica, São Paulo, v.1, n.1, art.2, jan./jun. 2008.

YIN, R. K. Estudo de caso: planejamento e métodos. Tradução Ana Thorell; revisão Técnica 
Cláudio Damacena. - 4. ed.- Porto Alegre: Bookman, 2010.

ZYLFIJAJ, K.; NIKOLOSKI, D. The impact of access to finance in performance of formal and informal SMES: Evidence from Kosovo. In: International Balkan and Near Eastern Social Sciences Conference Series, 2016, Bulgária. Anais... Bulgária, 2016. 